\title{
Co-production of knowledge and transformative learning towards a sustainable Asia
}

\author{
Mochamad Indrawan ${ }^{\mathrm{a}}{ }$, Dicky Sofjan $^{\mathrm{b}}$ \\ ${ }^{\text {a }}$ Research Center for Climate Change (RCCC), FMIPA - Faculty of Sciences, Universitas Indonesia, Depok, Indonesia \\ ${ }^{\mathrm{b}}$ Indonesian Consortium for Religious Studies (ICRS), Graduate School of Universitas Gadjah Mada (UGM), Yogyakarta, \\ Indonesia \\ *Corresponding author. Email: mochamad.indrawan@gmail.com.
}

\section{ABSTRACT}

In Asia, sustainable development has yet to find its critical mass. Non-state actors have the opportunity to catalyze change by awakening their collective consciousness through mutual learning and shared experiences. Initiated by Chulalongkorn University in Bangkok and the Indonesian Consortium for Religious Studies (ICRS) in Yogyakarta, a civic engagement project-involving partners and networks in Southeast Asia and Japan-was created to capture sustainable development initiatives from the ground, with a view towards strategic policy advocacy for a more sustainable Asia. The project aimed to bridge knowledge gaps by bringing together all relevant state and societal stakeholders to learn from one another and share their experiences, stories and narratives about change and self-transformation. Through a series of workshops, focus group discussions (FGDs), NGO fora and mayors' symposia since 2015, the project resulted in an accumulation of knowledge that has the potential to galvanize the various efforts to push the sustainable development agenda forward on the ground. The collaboration of many partners and relevant stakeholders overall met its intended outcome by generating an ad hoc centre for the co-production of knowledge on sustainability and a "transformative learning" platform. This was achieved by acknowledging the existence of various systems of knowledge, disciplines, and occupations while appreciating the tacit knowledge and unique insights coming from all participating partners, including the mayors, regents and local officials, and their civil society counterparts.

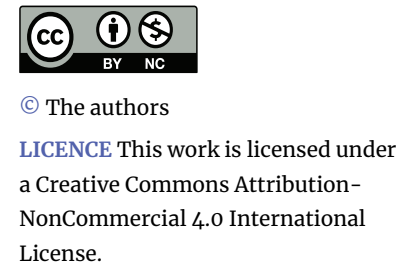

DOI 10.30852/sb.2021.1700

RECEIVED 12 May 2021 PUBLISHED (HTIML) 17 December 2021 PUBLISHED (PDF) 17 December 2021

CITATION Indrawan, M., \& Sofjan, D. (2021). Co-production of knowledge and transformative learning towards a sustainable Asia. APN Science Bulletin, 11(1), 125 - 132. doi: 10.30852/sb.2021.1700

\section{KEYWORDS}

Sustainable development, Asia, Civic engagement, Co-production of knowledge, Transformative learning, Mayors' symposium 


\section{HIGHLIGHTS}

- This collaborative project addressed a lacuna in civic engagement and aimed to strengthen the co-production of knowledge on sustainability and crystalize the process of transformative learning among the stakeholders in the region.

- One of the key strategies was to facilitate the building of a platform that could facilitate a meaningful interface between local authorities such as mayors and regents and their development counterparts, including civil society.

Through the co-production of knowledge and transformative learning, the project team generated many deep reflections and new insights into the inner workings of sustainability (Mezirow, 1991).

- The inspiring stories and narratives of change were conveyed in an edited book, policy briefs, and a monograph written by NGO activists, expert practitioners, scientists, and public intellectuals from the region.

- Co-production of knowledge provides the coming together of ideas and visions of people from different backgrounds and institutional affiliations.

\section{INTRODUCTION}

The concept of this project came from the growing concern among public intellectuals in Asia regarding the challenges of sustainability facing the region and the world. Public intellectuals were witnessing chronic disconnections among the regions' state and non-state actors such as national policymakers and local governments, academic institutions and civil society, including local grassroots communities. This is not to mention the international community, which has its own normative thinking, policy infrastructures and worldwide strategy through the proliferation of the Sustainable Development Goals (SDGs).

The project aimed to bridge knowledge gaps by bringing together all relevant state and societal stakeholders to learn from one another and share their experiences, stories and narratives about change and self-transformation. This approach allowed various stakeholders, both from the region and beyond, to co-produce knowledge on sustainability while transforming their thinking and learning about the issues from a multitude of perspectives, disciplines and unique experiences. In the field of sustainability, coproduction of knowledge is viewed in a general way as part of a gradually developing group of approaches, including transdisciplinary and joint knowledge production, participatory research, interactive research, action research, civic science, post-normal science, translational ecology and engaged scholarship (inter alia Gibbons et al., 1994 and Norström, 2020). Such an inclusive and participatory approach laid the groundwork for robust scientific outputs and strategic outcomes for the region. Inadvertently, this has facilitated a sense of collective consciousness, allowing mental and intellectual flexibility in advocating and mainstreaming sustainable development policies and outcomes across Southeast Asia and Japan.

In realizing these goals, emphasis was placed on a mutually transforming learning process. We applied Mezirow's rationale that at the heart of "transformation" rests a wise interrogation of 
deeply-held assumptions and perspectives. To allow for such adequate "learning", a shift in perspective would require open exchanges among peers, while guided by the quest for meaning and for legitimate solutions-rather than by the instructions of the market or the state- therefore orienting towards action (Wun'gaeo, Indrawan, Luzar, Hanna, \& Mayer, 2020).

\section{METHODS}

In order to showcase sustainable development innovations from the ground, the project was informed by the tacit knowledge of stakeholders, the various scientific enterprises by academics and researchers and the unique experiences of multifarious civil society actors. A series of reflections, discussions and documentation were enabled through the collaboration of civil society leaders from Southeast Asia and Japan, whereby they began the process of synthesising various onthe-ground sustainable development issues and solutions.

In 2015, the regional project "Transformative Learning Towards a Just and Sustainable ASEAN Community", led by Chulalongkorn University, launched a series of events. Later, these were connected to the Bangkok Forum held in 2018, where Chulalongkorn University raised the issue of future "social sustainability in Asia". Around 800 participants, including dignitaries of strategic world organizations and young people from around the world, attended the Bangkok Forum.

Together with Chulalongkorn University, ICRS hosted a regional workshop entitled "Civic Engagement for a Just and Sustainable ASEAN: Our Stories and Practices" in Yogyakarta, Indonesia, on 11-14 August 2017. This event was followed by a subsequent event entitled "Civic Engagement 4.0: Justice, Dignity and Sustainability" on 19-23 August 2019 in Solo, Central Java, Indonesia, which comprised an NGO forum and a mayors' symposium. Soon after, another major event took place in Denpasar, Bali, on "Co-Designing Sustainable, Just and Smart Urban Living" on 6-8 April 2021, which mainly emulated the Solo activities. However, due to the COVID-
19 pandemic, social restriction measures, the Bali events were convened in a hybrid format, allowing participants, including mayors and regents, to participate through an online platform.

While the participants in the first major event comprised around 25 high-level individuals, the latter two events involved hundreds of participants, including grassroots community leaders. Over 30 organizations from Southeast Asia, Japan, Canada, the USA, Australia, the UK, Kenya and other countries participated actively in the event. They shared their research, reflections, thoughts, experiences, stories and narratives on sustainability. Participants of the latter two events also included around 20 mayors, regents and representatives of local governments from Indonesia, Thailand and the USA. Some of the leading questions and issues raised in these events included the following:

- What are the main problems or issues of sustainability perceived by civil society in the Asian region? What are the key strategies and methods of engagement to interface with the national and local governments? Who or what are their primary targets?

- What are some of the internal and external factors and circumstances that have helped facilitate (or limit) these desired changes in the short- and long-term? What are some of the desired attitudinal, social and policy changes? How are these changes 'measured' and assessed?

- What about social justice, inclusion and gender? How could they be incorporated into the thinking and strategies of sustainability?

- How do governance and leadership play a role in pushing the agenda for sustainability in cities and regencies? What sustainability transition policies are in place? And how could civil society take a proactive role in the whole endeavour?

The above list comprised open-ended questions that we anticipated would not be fully answered in one or two workshops or a conference. However, the deliberations and interface among the stakehold- 
ers placed a high premium on the co-production of knowledge and transformative learning, where individuals, groups and organizations then depart with new realizations, knowledge, perspectives and a refreshed outlook in life and living.

Furthermore, local stories and narratives tend to be more appealing than the usual global normative mantras, such as the SDGs with their 17 targets and 169 target indicators. This was aptly summarized by Vannarith, Yin, and Mayer (2020), who wrote, "Successful on-the-ground resolution by a local group will provide a model to be studied, emulated, and applied by others - which may be in different localities but happened to be in a similar situation."

\section{RESULTS}

The knowledge products included an edited volume, two policy briefs, a monograph and a series of public and media outreach activities. The primary readership of the book includes regional policymakers, scientists, scholars, youth and practitioners endeavouring to consider sustainable development within the Asian context for potentially creative and transformative processes led by concerned citizens and activists at the grassroots level.

\subsection{The book}

The edited volume, entitled Civic Engagement in Asia: Transformative Learning in The Quest for a Sustainable Future, comprises 24 chapters, which capture sustainability practices around the region (Wun'gaeo et al., 2020) (See Figure 1 and Table 1). The chapters address topics such as resilient cities and sustainable urban planning, natural resources management and social enterprise, social and religious harmony, disaster mitigation and human trafficking, capacity building and networking support for civil society groups, knowledge creation and sharing, and leadership sharing (Vannarith et al., 2020). The diversity of issues was displayed through reflections on indigenous peoples and local communities, youth, women, artisans, volunteers, labour workers, teachers, students and religious communities, characterized by multiyear collaborative knowledge production and civic activism (Hapsari, Sofjan, \& Mayer, 2021).

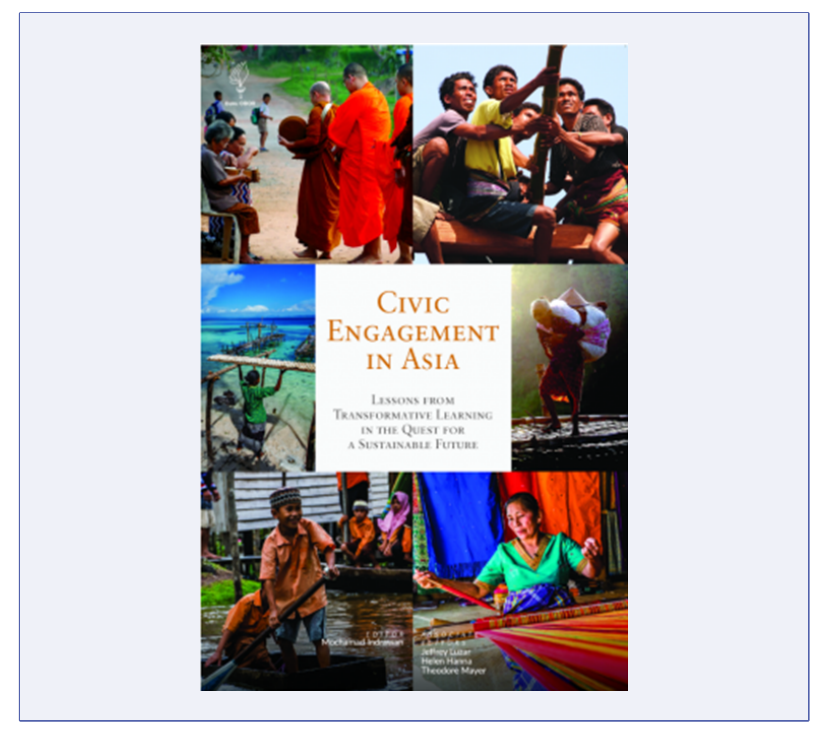

FIGURE 1. Edited volume resulting from the first civic engagement series discussions culminatingin a 2017 workshop in Yogyakarta.

\subsection{Policy briefs}

Two outputs from activists from the ASEAN member countries have already been completed in 2021:

- Biodiversity Conservation and Culture Nexus are Worthy of Local Economic Development, which takes the case of supporting woven clothing made by women artisans from East Sumba (Indonesia), emphasizing that capitalizing on the nexus between biodiversity and culture could help a district to become a prosperous and iconic responsible travel destination (Kirana, 2020).

- Dealing with Contamination: The Thailand Perspective - advocating a response to the toxic waste issue through reformed law and resolutions, and remediation measures (Saetang, 2020).

\subsection{Monograph}

A forthcoming monograph reflects on the process of the NGO fora and mayors' symposia (Sofjan et al., in press) held in 2019 and 2021. The monograph makes mention of the need to meaningfully 


\begin{tabular}{|c|c|c|}
\hline Chapter & Title & Authors \\
\hline 1 & Building Livelihood Sovereignty for the Mekong Region & Tran Thi Lanh \\
\hline \multirow[t]{3}{*}{2} & Building Recognition for the Resource Rights of Indigenous & Antoinette G. Royo, Andhika Vega \\
\hline & Peoples and Local Communities & Praputra, Joan Jamisolamin, Neni \\
\hline & & Rochaeni \\
\hline 3 & The Heartware of Ecological Sustainability in the Asian Context & Dicky Sofjan \\
\hline 4 & Transformative Learning for Thailand's Small-scale Farmers & Supa Yaimuang \\
\hline \multirow[t]{2}{*}{5} & The Role of Citizen Science in Policy Advocacy \& Building Just and & Penchom Saetang \\
\hline & Ecologically Sustainable Communities in Thailand & \\
\hline \multirow[t]{2}{*}{6} & Creating an Enabling Environment for Lao Youth to Engage with & Khamphoui Saythalat \\
\hline & the Community Development Process & \\
\hline \multirow[t]{2}{*}{7} & How Biodiversity and Culture can Fuel Economic Prosperity: the & Chandra Kirana \\
\hline & Case of Traditional Textile Artisans of East Sumba, Indonesia & \\
\hline \multirow[t]{2}{*}{8} & Localizing the Sustainable Development Goals: The Case of a & Nestor Castro \\
\hline & Community in Quezon City, Philippines & \\
\hline \multirow[t]{2}{*}{9} & Facilitating Household-level Biogas Production: a Case Study & Niken Arumdati \\
\hline & From the Indonesian Island of Lombok & \\
\hline 10 & Urban Reform in Indonesia & Ahmad Rifai \\
\hline 11 & A Decade of Fighting Box Jellyfish Health Issues & Lakkana Thaikruea \\
\hline \multirow[t]{2}{*}{12} & Citizens' Initiatives in the Fukushima Radiation Disaster: & Mariko Komatsu \\
\hline & Measuring and Sharing Fukushima & \\
\hline 13 & Democracy in the Wake of the Fukushima Nuclear Disaster & Hiroko Aihara \\
\hline \multirow[t]{2}{*}{14} & Fighting Modern Slavery in Southeast Asian Waters & Sompong Srakaew \& Patima \\
\hline & & Tungpuchayakul \\
\hline 15 & Female-driven Climate and Environmental Action: Champions & Areej Riaz \& Mairi Dupar \\
\hline & from Pakistan & \\
\hline 16 & Development Challenges in Papua and West Papua & Alex Rumaseb \\
\hline \multirow[t]{2}{*}{17} & In These Troubled Times, Could Every Classroom Become a Site of & Theodore Mayer \\
\hline & Transformation? The Story of the SENS Program & \\
\hline 18 & SENS and Its Impacts on Me: A Reflection from Karbi Anglong & Sabin Rongpipi \\
\hline \multirow[t]{3}{*}{19} & SENSing the Truth amidst a Crisis at the Personal, Social, and & Mahesh Amandkar \\
\hline & Environmental Crisis Levels: Learnings and Contributions & \\
\hline & Towards Sustainable Development in India in India & \\
\hline \multirow[t]{2}{*}{20} & Sustainability and Communities of Faith: Islam and & Fachruddin Majeri Mangunjaya \& \\
\hline & Environmentalism in Indonesia & Ibrahim Ozdemier \\
\hline \multirow[t]{2}{*}{21} & Policy Entrepreneurship for Sustainable Development in Malaysia: & Hezri Adnan \\
\hline & A Reflection & \\
\hline 22 & Step by Step from Cambodia Towards ASEAN & Heng Monychenda \\
\hline \multirow[t]{2}{*}{23} & Reflections on Civic Engagement and Key Issues & Chheang Vannarith \& Maung \\
\hline & & Maung Yin \\
\hline 24 & Civic Engagement for a Just and Sustainable ASEAN & Erna Witoelar \\
\hline
\end{tabular}

TABLE 1. Table of contents of the edited volume

engage the issues of sustainability, human dignity, social justice and smart cities while stressing the importance of transformative learning, open governance, democratic governance and servant leadership in civic engagement.

\subsection{Further outreach}

Further outreach and advocacy were undertaken through international conferences, including book discussions and a virtual book launch and discussions.

- "Community, Ecology and Religion: Interdisciplinarity and Civic Engagements towards Sustainable Living" in the $4^{\text {th }}$ International Conference of Interreligious and Intercultural Studies (ICIIS) at Universitas Hindu Indonesia, Denpasar, Bali, 
on 15 February 2020. See: https://www.apngcr.org/news/civic-engagement-in-asia-b ook-launch-held-in-indonesia/

- Virtual International Webinar and Book Discussion, organized by Universitas Indonesia - Faculty of Mathematics and Sciences, 28 August 2020

- Virtual International Webinar and Book Discussion, "Promoting Environmental Sustainability Through Social Science Perspective" in $2^{n d}$ International Conference on Social Science Education, organized by Universitas Lambung Mangkurat on 23 September 2020. See: https://www.icsse.u lm.ac.id

- One media article from a well-known portal, namely Mongabay in Indonesia. See: https:/ /www.mongabay.co.id/2021/03/09/masa-d epan-berkelanjutan-di-asia-pasca-covid-1 9-berkaca-dari-pengalaman-aktivis-lokal/

\section{DISCUSSION}

We consider the uniqueness of our approach rests in its iterative approach to delve into both concept and practice of civic engagement. Our probe was advanced through the series of regional dialogues: "Transformative Learning Towards a Just and Sustainable ASEAN Community" (Yogyakarta, 2015), "Bangkok Forum" (2018), "Civic Engagement 4.0: Justice, Dignity and Sustainability" (Solo, 2019), "Co-Designing Sustainable, Just and Smart Urban Living" (Denpasar, 2021). While it may be too early to establish sustainability outcomes from the project beyond a reasonable doubt, our progressively inclusive multi-stakeholders discussions did allow and, in fact, facilitated the clashing of cultural assumptions and interrogations of deeply embedded beliefs and perspectives. The coproduction of knowledge and co-designing process, along with the search for meaning and genuine solutions, helped improve the focus towards a wise and balanced form of collective action.

The series of regional, participatory and meaningful exchanges has set in motion a kind of "trans- formative learning" in Mezirow's parlance while simultaneously demonstrating the serious allocation of time, energy, investments and resources over an extended period of time by the various actors, partners and stakeholders. This attested to their commitment and propensity for change in the right direction.

\subsection{The building of momentum}

The NGO fora, held twice in Solo (2019) and Bali (2021), connected the intricate and complex web of civil society actors in the region working on sustainability. A mix of civil society actors, ranging from environmental activists to faith communities, youth leaders, disabled and women's groups, all participated in knowledge-sharing and storytelling. Their interface with mayors and regents in the two symposia also provided a glimpse of the power and positive role of civil society in aiding local governments to confront the challenges of sustainability while at the same time providing development solutions.

At least three principles emerged due to the two mayors' symposia: open governance, servant leadership and the role of faith in urban resilience. Open, democratic governance refers to the idea that managing development and change constitutes a collective endeavour, requiring inputs, feedback and criticisms from all concerned parties and stakeholders. The imperative for openness in democratic governance would ultimately lead to greater transparency, inclusion and meaningful civic engagement. Servant leadership suggests a mode of change from below. The idea that mayors and regents are mere servants of the people is not new but hardly articulated in contemporary times, most notably in Asia. Therefore, servant leadership denotes the willingness of the government to 'listen' attentively to the voices on the ground and the constructive criticisms on a wide range of governance issues. It also assumes that governments would, in all earnestness, respond to them favourably.

The third principle concerns the role of faith in urban resilience, which seems counter-intuitive to many. The World Urban Agenda (WUA) from 
UN-Habitat, for instance, does not make any mention of faith, religion or spirituality. Its underlying assumptions likely foresee urban centres as wholly secular. This assertion is, of course, baseless. In the United States of America, according to a Gallup Poll survey conducted in 2011, "more than nine in 10 Americans continue to believe in God". Meanwhile, most people in Western Europe say they "believe in God" although "believing in God does not necessarily mean belief in the God of the Bible" (Cooperman \& Sahgal, 2018). To assume that religion, faith and spirituality are irrelevant to sustainability seems to hold no logic or scientific prudence. In fact, based on The Future of World Religions: Population Growth Projections, 2010-2050 (Hackett et al., 2015), it is said that "Muslims are rising fastest and the unaffiliated are shrinking as a share of the world's population". This only goes to show that religion or faith communities are perhaps the most sustainable human institutions ever to exist and flourish, until today.

\subsection{Co-production of knowledge}

In order to achieve impact, a book must be effectively distributed. The latter is a function of pricing and distribution range. We originally planned to publish one book through a reputable educationoriented publisher (Yayasan Pustaka Obor, Indonesia) to allow commercially friendly access. Fortunately, Springer also showed interest in republishing and distributing the book worldwide.

As intended, the edited volume managed to showcase the contributions of non-state actors on the ground and inadvertently highlighted the years of transformative learning that has unfolded and benefited those who participated in the various events held throughout the past five years. As beautifully commented by the reviewer to the Springer edition (Indrawan, Luzar, Hanna, \& Mayer, in press), Dr Julian Caldecott:

"The community orientation is consistent and strong, reminding us that our lives really only make sense in a social and ecological context. The result is that the book bears comparison with the foundational volume The Wealth of Communities:
Stories of Success in Local Environmental Management by Pye-Smith, Borrini, and Sandbrook (1994). This places it within a current renaissance of appreciation for community-based environmental management, which is fast becoming prominent as a key way for societies to adapt to climate change and ecological chaos."

As pointed out by Hapsari et al. (2021), civic engagement is, after all, a political project that calls for the ability to deal with both structural and cultural challenges to the sustainability agenda, of which civil society actors provide an important lever. In effect, civic engagement in sustainability can provide a strong nexus of ideas and discourses as long as platforms are continually built around the subject matter. Due to the nature of sustainability being an all-encompassing norm, the coproduction of knowledge and transformative learning, which stress the importance of proactive and deep listening, could be held as a basic premise to meaningful civic engagement. Evidence from the project suggests that sustainability in Asia could be attainable if all partners and relevant stakeholders were engaged in a mutual learning platform to reflect on their tacit knowledge, experiences, local stories and narratives. Effective collaboration and synergy among actors and participants are most certainly needed to ensure that sustainable development learning takes place across local communities throughout Asia.

\section{CONCLUSION}

Through a series of workshops, focus group discussions, NGO fora and mayors' symposia, followed by publications and write-ups by project participants, new knowledge, inspiring stories and narratives related to SDGs on the ground have emerged as part of the collective consciousness of those who are pro-actively supporting and promoting sustainability in the region. The realization and crystallization of a new 'movement' in the region, which is dedicated to sustainability in and of itself, is undoubtedly a positive development and trajectory in Asia that needs to be acknowledged and appreciated. 
The question of whether or not such movements would sustain themselves is a different issue altogether. At the very least, though, participation of multi-stakeholders, including local decisionmakers and civil society actors, provided a clear message that in meeting the common goal of sustainability, there are contexts, multiple interests and approaches to every issue, all of which may be interwoven and strengthened by active engagement and mutual learning among the relevant actors and stakeholders. Yet clearly, the outputs and outcome of the project have given us the much-needed empirical perspective, hope and confidence in the future of co-production of knowledge and transformative learning in the region.

\section{ACKNOWLEDGEMENT}

This project was supported by APN - AsiaPacific Network for Global Change Research - in cooperation with the Institute of Asian Studies Chulalongkorn University, Japan Foundation Asia Center, Chula Global Network, Indonesian Consortium for Religious Studies (ICRS), and Ford Foundation. We thank Surichai Wun' Gaeo, Michiko Yoshida, Toshiyuki Doi, Theodore Mayer, Yeoh Seng Guan, Linda Stevenson, Christmas Uchiyama for continued facilitation. For editorial assistance, we thank Jeffrey Luzar. We also convey our deep appreciation to the Bulletin's anonymous reviewers, who provided highly constructive feedback.

\section{REFERENCES}

Cooperman, A., \& Sahgal, N. (2018). Being Christian in western Europe. Pew Research Center.

Gibbons, M., Limoges, C., Nowotny, H., Schwartzman, S., Scott, \& Trow, M. (1994). The new production of knowledge: The dynamics of science and research in contemporary societies. Los Angeles: Sage.
Hackett, C., Connor, P., Stonawski, M., Skirbekk, V., Potančoková, M., \& Abel, G. (2015). The future of world religions: Population growth projections, 20102050. Retrieved from http://www.pewforum.org/ 2015/04/02/religious-projections-2010-2050/

Hapsari, M., Sofjan, D., \& Mayer, T. (2021). Venturing sustainability: Political lessons from civic engagement and transformative learning in Asia. APN Science Bulletin, 11(1). doi:10.30852/sb.2021.1543

Indrawan, M., Luzar, J., Hanna, H., \& Mayer, T. (in press). Civic engagement in Asia: Lessons from transformative learning in the quest for a sustainable future. Springer.

Kirana, C. (2020). Biodiversity conservation and culture nexus is worthy of local economic development. Policy Brief. Sekar Kawung Foundation.

Mezirow, J. (1991). Transformative dimensions of adult learning. San Francisco: Jossey Bass Publishers.

Norström, A.V. (2020). Principles for knowledge coproduction in sustainability research. Nature Sustainability, 3, 182-190. doi:10.1038/s41893-019-0448-2

Pye-Smith, C., Borrini, G., \& Sandbrook, R. (1994). The wealth of communities: Stories of success in local environmental management (1st ed.). Routledge. doi:10.4324/9781003144267

Saetang, P. (2020). Dealing with contamination: The Thailand perspective. Policy Brief. Ecological Alert and Recovery - EARTH.

Sofjan, D., Epafras, L.C., Hussein, F., Bagir, Z.A., Astuti, I.F., Marsiyanti, A., \& Kaunang, E. (in press). Co-designing sustainable, just and smart urban living.

Vannarith, C., Yin, M.M., \& Mayer, T. (2020). Reflections on civic engagement and key issues raised in this volume. In Indrawan, M., Luzar, J., Hanna, H., ... T. (Eds.), Civic Engagement in Asia: Lessons from Transformative Learning in the Quest for a Sustainable Future (pp. 293307). Yayasan Pustaka Obor Indonesia.

Wun'gaeo, S., Indrawan, M., Luzar, J., Hanna, H., \& Mayer (2020). Foreword. In Civic Engagement in Asia: Lessons from Transformative Learning in the Quest for a Sustainable Future (pp. viii-xii). Yayasan Pustaka Obor Indonesia. 